\title{
Estimated glomerular filtration rate as one of the main predictors of in-hospital mortality in Egyptian patients with ST elevation myocardial infarction: a two-year retrospective study
}

\author{
Moheb Wadie ${ }^{1 *}$ (D, Emad Samaan², Mohammed Kamal Nassar ${ }^{2}$ and Mostafa Abdelsalam²
}

\begin{abstract}
Background: Renal dysfunction is one of the major causes of in-hospital mortality in STEMI patients. In this study, we evaluated the combined predictive value of eGFR by CKD-EPI equation and shock index for in-hospital mortality and other adverse clinical outcomes in Egyptian patients with STEMI.

Results: A total of 450 STEMI patients were divided into 2 groups according to their eGFR with a cutoff value of $60 \mathrm{ml} / \mathrm{min} / 1.73 \mathrm{~m}^{2}$ and compared as regards mortality, major bleeding, reinfarction, development of heart failure, stroke, and atrial fibrillation during the period of admission. Univariate analysis was performed to define significant factors that affected mortality; then, significant factors were subjected to a multivariate logistic regression.

Patients with eGFR $<60 \mathrm{ml} / \mathrm{min} / 1.73 \mathrm{~m}^{2}$ had higher rates of mortality $(P<0.0005)$ and atrial fibrillation $(P=.006)$ during the hospital admission. A multivariate logistic regression model showed the predictors of mortality were factors $\mathrm{SI}(\mathrm{OR}=$ $28.56,95 \% \mathrm{Cl} 8-101.97, P<0.0001)$, cardiac troponin $(\mathrm{OR}=2.89$, 95\% Cl 1.08-7.77, $P=0.03)$, age $(\mathrm{OR}=1.07,95 \% \mathrm{Cl} 1.02-$ $1.2, P=0.002)$, and eGFR (OR $=0.98,95 \% \mathrm{Cl} 0.96-0.99, P=0.04)$.

Conclusions: Estimated GFR $<60 \mathrm{ml} / \mathrm{min} / 1.73 \mathrm{~m}^{2}$ in STEMI patients is associated with higher rate of mortality. Estimated GFR, age, shock index, and cardiac troponin were the most significant predictors of mortality in STEMI patients
\end{abstract}

Keywords: Estimated GFR, Shock index, Troponin, CKD-EPI, STEMI

\section{Background}

Coronary artery disease (CAD) is one of the major contributors of morbidity and mortality burden [1]. Within the spectrum of CAD, ST elevation myocardial infarction (STEMI) represents the major risk for adverse events and mortality [2].

Many factors affect the mortality in STEMI patients such as age, heart failure (HF), pre-hospital delay,

\footnotetext{
* Correspondence: Muheb2001@hotmail.com

'Department of Cardiology, Faculty of Medicine, Mansoura University,

Mansoura, Egypt

Full list of author information is available at the end of the article
}

treatment strategy, diabetes mellitus (DM), anatomy of the affected coronary arteries, and renal function [3]. Constructing risk prediction models from these factors is beneficial for planning management strategies and determining the prognosis [4].

The relationship between renal dysfunction and increased mortality in STEMI patients is well established, and renal function estimation is mandatory to risk stratify STEMI patients [2]. Estimated glomerular filtration ratio (eGFR) by the Modification of Diet in Renal Disease equation has been correlated with prognosis of STEMI patients [5], and eGFR from Chronic Kidney

\section{Springer Open}

() The Author(s). 2020 Open Access This article is licensed under a Creative Commons Attribution 4.0 International License, which permits use, sharing, adaptation, distribution and reproduction in any medium or format, as long as you give appropriate credit to the original author(s) and the source, provide a link to the Creative Commons licence, and indicate if changes were made. The images or other third party material in this article are included in the article's Creative Commons licence, unless indicated otherwise in a credit line to the material. If material is not included in the article's Creative Commons licence and your intended use is not permitted by statutory regulation or exceeds the permitted use, you will need to obtain permission directly from the copyright holder. To view a copy of this licence, visit http://creativecommons.org/licenses/by/4.0/. 
Disease Epidemiology Collaboration (CKD-EPI) equation has been validated as a more simple and accurate marker of renal function [6].

Shock index (SI) is a simple index that means the ratio of heart rate (HR) to systolic blood pressure (SBP). This index has shown a good predictive value for hospital mortality in many critical situations, including trauma [7], pulmonary embolism [8], aortic dissection [9], and STEMI [10].

In the present study, we aimed to assess eGFR by CKD-EPI equation and SI (a simple clinical index) as predictors for in-hospital mortality and other adverse clinical outcomes in Egyptian patients with STEMI from the local STEMI registry and their impact on the initial risk stratification and management in our developing country.

\section{Methods}

This is a retrospective observational study carried out at the Cardiovascular Department. A total of 450 consecutive STEMI patients were recruited between March 2016 and March 2018. All demographic and basic clinical and biochemical characteristics of the STEMI participants were retrospectively analyzed.

Patients who fulfilled the following criteria were included: (a) diagnosis of STEMI according to ACCF/ AHA Guideline for the Management of STEMI where 290 patients received thrombolytic therapy, 74 treated by primary PCI, 32 had PCI after failed thrombolytic, and 54 patients did not receive thrombolytic therapy or PCI due to late presentation or presence of a contraindication [11] and (b) aged $>18$ years and the data were collected from the electronic medical record of specialized medical hospital of cardiovascular department.

\section{Data collection}

All patients were retrospectively analyzed depending on the following: (a) general data, e.g., age, gender, body mass index (BMI), smoking status, duration of hospital admission, and history of other medical disorders; (b) diagnosis on admission, e.g., cardiac condition, cardiac complications (arrhythmia, HF, pulmonary edema), DM, dyslipidemia, and hypertension (HTN); (c) vital data on admission, e.g., SBP, diastolic blood pressure (DBP), and basal HR; and (d) biochemical data on admission to avoid the effect of treatment on the results including serum creatinine, random blood sugar, creatine kinase (CK-MB), qualitative troponin, uric acid, and lipid profile. eGFR was calculated at the time of admission using CKD-EPI 2009 creatinine equation [6]. Physiological predictors as mean arterial pressure (MAP), shock index $(\mathrm{SI})=(\mathrm{HR} / \mathrm{SBP})$, modified SI $(\mathrm{MSI})=(\mathrm{HR} / \mathrm{MAP})$, and age $-\mathrm{SI}($ age $-\mathrm{SI})=($ age $\times$ SI $)$ were calculated. Killip class was calculated as class I represents those with no signs of HF; class II is for those with rales in the lungs, an S 3 gallop, and elevated jugular venous pressure; class III describes patients with acute pulmonary edema; and class IV describes individuals in cardiogenic shock or hypotension (measured as SBP $<90 \mathrm{mmHg}$ ) and evidence of low cardiac output [12].

\section{Study design}

Study participants were divided into two groups based on eGFR at admission: group I (eGFR $\geq 60 \mathrm{ml} / \mathrm{min} / 1.73 \mathrm{~m}^{2}$ ) and group II (eGFR $<60 \mathrm{ml} / \mathrm{min} / 1.73 \mathrm{~m}^{2}$ ).

\section{Outcome measures}

Patients were evaluated for the following outcomes:

(a) Primary outcome: in-hospital mortality

(b) Secondary outcomes: occurrence of complications, contrast-induced acute kidney injury (AKI) according to KDIGO definition [13], major bleeding after percutaneous coronary intervention (PCI), in-hospital reinfarction, $\mathrm{HF}$, cerebrovascular accident, and atrial fibrillation (AF)

\section{Statistical analysis}

Data were collected, revised, verified, then analyzed using the Statistical Package of Social Sciences (SPSS) version 21 for Windows (SPSS, Inc., Chicago, IL, USA). Median, mean, and standard deviation (SD) were used for all quantitative values and/or number of cases while percentage for qualitative values. The distribution of tested variables was examined with Kolmogorov-Smirnov test for normality. The significance of differences between continuous variables was determined with independent samples $t$ test for parameters with normal distribution and Mann-Whitney test for not normally distributed variables, as appropriate. The chi-square or Fisher exact test was used for comparison between qualitative variables, as appropriate. Univariate analysis was performed to define significant factors that affected mortality; then, 4 significant factors, comprising a mix of demographic, clinical, and laboratory factors, were subjected to a multivariate logistic regression model. The goodness of fit for the model was tested using Hosmer-Lemeshow goodness of fit test (Table 1). Receiver operating characteristic (ROC) curve analysis was done for eGFR to identify the cut points below which mortality is likely. $P$ values $<0.05$ were considered significant for all statistical analyses in this study.

Table 1 Hosmer and Lemeshow test

\begin{tabular}{llcc}
\hline Step & Chi-square & df & Sig. \\
\hline 1 & 8.611 & 8 & .376 \\
\hline
\end{tabular}




\section{Results}

The study population were divided into 2 groups according to eGFR on admission: group I with eGFR $\geq 60 \mathrm{ml} /$ $\mathrm{min} / 1.73 \mathrm{~m}^{2}$ (354 patients) and group II with eGFR $<60$ $\mathrm{ml} / \mathrm{min} / 1.73 \mathrm{~m}^{2}$ (96 patients).

\section{Characteristics of the cohort}

All the basic and clinical characteristics of the STEMI patients who had undergone PCI are shown in Table 2. Group II patients were significantly older $(P<0.0001)$ and have a higher percentage of female gender, DM, HTN, AF, and history of malignancy or previous hemodialysis $(P \leq 0.0001,0.01,<0.0001,0.002,0.02$, and 0.006 respectively) and a lower percentage of smokers $(P$ $=0.001)$, while the other parameters, like dyslipidemia, previous $\mathrm{MI}, \mathrm{PCI}$, coronary artery bypass graft surgery, stroke, peripheral vascular disease, congestive HF, and other factors, did not show any significant difference between the two groups.

Group II patients had significantly lower DBP, eGFR, hemoglobin (HB), total cholesterol, and low-density lipoprotein cholesterol $(P=0.04,<0.0001,0.005,0.004$, and 0.008 respectively) and a significantly higher serum creatinine, random blood sugar, uric acid, CK-MB, and percentage with positive troponin on admission $(P \leq 0.0001$, $<0.0001,<0.0001,0.03$, and 0.001 respectively). Other parameters like HR, SBP, ejection fraction, and others did not have any statistically significant difference between both groups (Table 2).

Regarding the primary outcome of this study, mortality was significantly higher in group II $(P<0.0001)$ (Table 3$)$. The highest mortality rate was observed in patients who did not receive any reperfusion therapy $[n=12(22.2 \%)]$ with no significant difference between other types of reperfusion therapy (Table 4). Regarding the secondary outcomes, none of our patients developed AKI after contrast administration. In-hospital HF and AF were significantly higher in group II ( $P=0.02$ and 0.006 respectively), while major bleeding, in-hospital reinfarction, and cerebrovascular accident did not differ between both groups.

Significant predictors that affected mortality on a univariate analysis of 16 clinical, laboratory, and physiological parameters were age $(P<0.0001)$, sex $(P=$ $0.002)$, HB $(P<0.0005)$, cardiac troponin $(P=0.006)$, CK-MB $(P=0.04)$, eGFR $(P<0.1)$, MAP, SI, MSI, AGESI, and Killip $(P<0.0001)$ (Table 5).

Multivariate logistic regression model defining significant predictors for mortality was highly significant $(P<$ $0.0001)$ (Table 6). The significant factors were SI $(P<$ 0.0001 , $\mathrm{OR}=28.56)$, cardiac troponin $(P=0.03$, OR $=$ $2.89)$, age $(P=0.002$, OR $=1.07)$, and eGFR $(P=0.04$, $\mathrm{OR}=0.98)$ (Table 6). ROC curve analysis was done for eGFR with a value of $69.5 \mathrm{ml} / \mathrm{min} / 1.73 \mathrm{~m}^{2}$ or less identifies the probability of mortality with $69 \%$ sensitivity and $73 \%$ specificity (Fig. 1).

\section{Discussion}

STEMI has high morbidity and mortality. Risk stratification is of extreme importance for better patient outcome [14]. Our goal was to test some of the previously reported predictors of mortality in STEMI patients in an Egyptian cohort. We specified 16 risk factors according to the data available in our archive. They were divided into clinical, biochemical, and physiological predictors. Univariate analysis was performed to define significant factors that affected mortality. We then selected 4 factors with the highest coefficients and odds ratios to construct a multivariate prediction model. The selection of only four factors was based on the standard statistical equation for building a well-fitted multivariate prediction model respecting the tested variables to sample size ratio [15]. We have paid special attention to eGFR calculated by CKD-EPI equation as an independent predictor of mortality and other adverse outcomes.

\section{Clinical predictors of mortality \\ Effects of age and gender on the in-hospital prognosis of STEMI patients}

The age was an independent risk factor of mortality in the present study, which is similar to previous recently published reports $[16,17]$. Logically, aging is associated with chronic comorbidities and pathological changes in some organs, which affect the patient outcome and response to tissue injury and treatment, either directly or indirectly. Recent results of a systematic review and meta-analysis of 24 studies (430,914 STEMI patients) showed that the in-hospital mortality of male patients was significantly lower than that of females [18]. In consistence with these observations, we reported the same worse prognosis for females than males. In our cohort, the STEMI females were significantly older than the STEMI males. Also, the rates of having other diseases such as DM and HTN were higher in females. Previous studies showed that DM [19], HTN [20], and dyslipidemia were significant risk factors of mortality in STEMI patients. We did not find, any of them, having a significant impact on in-hospital mortality. Based on our analysis of the clinical predictors, we chose the age factor to share in the multivariate prognostic model construction for prediction of mortality in our cohort.

\section{Effects of eGFR by CKD-EPI equation on the in-hospital prognosis of STEMI patients}

The renal dysfunction in STEMI patients is a wellknown predictor for the in-hospital and long-term mortality [21]. Also, the level of serum creatinine is one of the prognostic predictors after treatment $[11,22]$. This 
Table 2 Characteristics of the cohort compared according to eGFR levels

\begin{tabular}{|c|c|c|c|}
\hline Parameter & $\begin{array}{l}\text { Group } 1 \text { (eGFR } \\
\geq 60 \mathrm{ml} / \mathrm{min} / \\
1.73 \mathrm{~m}^{2} \text { ) }\end{array}$ & $\begin{array}{l}\text { Group } 2 \text { (eGFR } \\
<60 \mathrm{ml} / \mathrm{min} / \\
1.73 \mathrm{~m}^{2} \text { ) }\end{array}$ & $P$ \\
\hline Number (n) (\%) & $354(78.6 \%)$ & 96 (21.4\%) & \\
\hline Age (years) & $54.79 \pm 10.4$ & $64.94 \pm 9.16$ & $<0.0001^{* *}$ \\
\hline \multicolumn{4}{|l|}{ Gender } \\
\hline Male & 305 (86.2\%) & 68 (70.8\%) & $<0.0001^{* *}$ \\
\hline Female & $49(13.8 \%)$ & $28(29.2 \%)$ & \\
\hline Smoking & $216(61 \%)$ & $40(41.7 \%)$ & $0.001^{*}$ \\
\hline Diabetes mellitus & 141 (39.8\%) & $51(53.1 \%)$ & $0.01^{*}$ \\
\hline Hypertension & $122(34.5 \%)$ & $55(57.3 \%)$ & $<0.0001^{* *}$ \\
\hline BMI $\left(\mathrm{kg} / \mathrm{m}^{2}\right)$ & $29.17 \pm 4.99$ & $30.16 \pm 5.72$ & 0.12 \\
\hline $\mathrm{AF}$ & $9(2.5 \%)$ & $9(9.4 \%)$ & $0.002^{*}$ \\
\hline PVD & $1(0.3 \%)$ & $2(2.1 \%)$ & 0.054 \\
\hline CHF & $1(0.3 \%)$ & $2(2.1 \%)$ & 0.054 \\
\hline Thyroid illness & $2(0.6 \%)$ & $2(2 \%)$ & 0.13 \\
\hline Malignancy & $3(0.8 \%)$ & $4(4.2 \%)$ & $0.02^{*}$ \\
\hline Hemodialysis & 0 & $2(2.1 \%)$ & $0.006^{*}$ \\
\hline Sleep apnea & $1(0.3 \%)$ & 0 & 0.6 \\
\hline Previous MI & $16(4.5 \%)$ & $8(8.3 \%)$ & 0.14 \\
\hline Previous angina & $43(12.1 \%)$ & $15(15.6 \%)$ & 0.36 \\
\hline Previous PCI & $12(3.4 \%)$ & $4(4.2 \%)$ & 0.71 \\
\hline Previous CABG & $3(0.8 \%)$ & 0 & 0.36 \\
\hline Previous stroke & $18(5.1 \%)$ & $7(7.3 \%)$ & 0.4 \\
\hline Admission duration (days) & $4(1-13)$ & $4(1-11)$ & 0.86 \\
\hline
\end{tabular}

Baseline clinical and laboratory data on admission

\begin{tabular}{|c|c|c|c|}
\hline HR (beats/minute) & $82.92 \pm 19.12$ & $81.66 \pm 25.21$ & 0.64 \\
\hline SBP $(\mathrm{mmHg})$ & $120.36 \pm 24.17$ & $117.08 \pm 31.31$ & 0.34 \\
\hline $\mathrm{DBP}(\mathrm{mmHg})$ & $76.17 \pm 13.96$ & $72.7 \pm 18.55$ & $0.04^{*}$ \\
\hline MSI & $0.94 \pm 0.32$ & $1 \pm 0.46$ & 0.16 \\
\hline Ejection fraction (\%) & $51.34 \pm 9.2$ & $49.15 \pm 10.41$ & 0.06 \\
\hline RSWMA & $294(83.1 \%)$ & $80(83.3 \%)$ & 0.63 \\
\hline Creatinine (mg/dl) & $0.9(0.6-1.2)$ & $1.5(0.7-7.2)$ & $<0.0001^{* *}$ \\
\hline eGFR $\left(\mathrm{ml} / \mathrm{min} / 1.73 \mathrm{~m}^{2}\right)$ & $91.5 \pm 17.98$ & $42.88 \pm 13.55$ & $<0.0001^{* *}$ \\
\hline RBS (mg/dl) & $177.41 \pm 75.68$ & $225.05 \pm 109.1$ & $<0.0001^{* *}$ \\
\hline HbA1c (\%) & $8.76 \pm 2.57$ & $8.95 \pm 2.74$ & 0.86 \\
\hline Uric acid (mg/dl) & $5.85 \pm 1.73$ & $7.94 \pm 2.05$ & $0.0001^{* *}$ \\
\hline Hemoglobin (gm/dl) & $13.99 \pm 1.74$ & $13.4 \pm 1.98$ & $0.005^{*}$ \\
\hline Neutrophil* $10^{3}$ & $8.5(0.62-26.5)$ & $8.9(0.9-26)$ & 0.62 \\
\hline Lymphocyte $* 10^{3}$ & $2.1(0.39-19.4)$ & $1.7(0.29-17.23)$ & 0.17 \\
\hline $\begin{array}{l}\text { Nutrophil/lymphocyte } \\
\text { ratio (NLR) }\end{array}$ & $2.8(0.52-17.2)$ & $2.67(0.6-4.74)$ & 0.55 \\
\hline Platelets* $10^{3}$ & $241(66-574)$ & $216(32-752)$ & 0.08 \\
\hline CK-MB (IU/L) & $60(12-1150)$ & $80.5(1-876)$ & $0.03^{*}$ \\
\hline $\begin{array}{l}\text { Positive troponin } \\
\text { (qualitative test) }\end{array}$ & $183(51.7 \%)$ & $67(69.8 \%)$ & $0.001^{*}$ \\
\hline Total cholesterol (mg/dl) & $203.41 \pm 50.86$ & $185.43 \pm 41.4$ & $0.004^{*}$ \\
\hline
\end{tabular}

Table 2 Characteristics of the cohort compared according to eGFR levels (Continued)

\begin{tabular}{llll}
\hline Parameter & $\begin{array}{l}\text { Group 1 (eGFR } \\
\geq 60 \mathrm{ml} / \mathrm{min} / \\
\left.1.73 \mathrm{~m}^{2}\right)\end{array}$ & $\begin{array}{l}\text { Group 2 (eGFR } \\
<60 \mathrm{ml} / \mathrm{min} / \\
\left.1.73 \mathrm{~m}^{2}\right)\end{array}$ & $P$ \\
\hline LDL-cholestrol $\mathbf{( m g / d l )}$ & $130.7 \pm 37.51$ & $112.43 \pm 34.11$ & $0.008^{*}$ \\
HDL-cholesterol (mg/dl) & $43.92 \pm 16.11$ & $46 \pm 17.3$ & 0.8 \\
Triglycerides (mg/dl) & $144(35-711)$ & $134.5(60-792)$ & 0.15
\end{tabular}

Data expressed as mean \pm SD, median (min-max), or number (\%) $B M I$ body mass index, $A F$ atrial fibrillation, $P V D$ peripheral vascular disease, $C H F$ congestive heart failure, $M I$ myocardial infarction, $P C$ percutaneous coronary intervention, $C A B G$ coronary artery bypass grafting, $H R$ heart rate, SBP systolic blood pressure, $D B P$ diastolic blood pressure, MSI modified shock index, RSMWA resting segmental wall motion abnormalities, eGFR estimated glomerular filtration rate, $R B S$ random blood sugar, $L D L$ low-density lipoprotein, $H D L$ high-density lipoprotein

${ }^{*} P<0.05$

${ }^{*} P<0.0001$

is, in addition to, the interest of many studies to question the role of the various known equations that estimate the GFR to predict the patient outcomes [23]. The currently recommended equation for the estimation of GFR is CKD-EPI [6]; our study showed that reduced eGFR using this equation significantly affected the inhospital prognosis of STEMI and eGFR below $60 \mathrm{ml} / \mathrm{min}$ was associated with about 4-fold increase in the mortality rate compared with those with eGFR above $60 \mathrm{ml} /$ min. The rates of in-hospital incident HF and AF are also significantly higher in those with eGFR below 60 $\mathrm{ml} / \mathrm{min}$. This could be explained by the fact that lower eGFR levels are associated with advanced age, HTN, and $\mathrm{DM}$ in addition to the impact of nephropathy itself due to extensive atherosclerosis, calcifications, multiple organ affection, and limitation of medication such as ACE or ARBs. Therefore, eGFR should be considered as important predictors of prognosis, and risk stratifications should be conducted based on the functional status of the kidneys to reduce mortality and improve the outcome in STEMI patients.

Table 3 Frequencies of different outcomes compared as regards eGFR levels

\begin{tabular}{llll}
\hline Parameter & $\begin{array}{l}\text { Group 1 (GFR } \\
\geq 60 \mathrm{ml} / \mathrm{min}) \\
354(78.6 \%)\end{array}$ & $\begin{array}{l}\text { Group 2 (GFR } \\
<60 \mathrm{ml} / \mathrm{min})\end{array}$ & \\
& $96(21.4 \%)$ & \\
\hline Mortality $\boldsymbol{n}$ (\%) & $\mathbf{1 7 ( 4 . 8 \% )}$ & $\mathbf{1 9 ( 1 9 . 8 \% )}$ & $<0.0001^{* *}$ \\
Major bleeding & $\mathbf{8 ( 2 . 3 \% )}$ & $\mathbf{5 ( 5 . 2 \% )}$ & $\mathbf{0 . 1 6}$ \\
Reinfarction (in-hospital) & $\mathbf{2 ( 0 . 6 \% )}$ & $\mathbf{1 ( 1 \% )}$ & $\mathbf{0 . 5}$ \\
Heart failure (in-hospital) & $\mathbf{2 1 ( 5 . 9 \% )}$ & $\mathbf{1 2 ( 1 2 . 5 \% )}$ & $\mathbf{0 . 0 2 *}$ \\
Stroke (in-hospital) & $\mathbf{4 ( 1 . 1 \% )}$ & $\mathbf{3 ( 3 . 1 \% )}$ & $\mathbf{0 . 1 7}$ \\
AF (in-hospital) & $\mathbf{9 ( 2 . 5 \% )}$ & $\mathbf{9 ( 9 . 4 \% )}$ & $\mathbf{0 . 0 0 6 *}$ \\
\hline
\end{tabular}

Data expressed as number (\%)

$A F$ atrial fibrillation

${ }^{*} P<0.05$

$* * P<0.0001$ 
Table 4 Effect of type of reperfusion therapy on mortality

\begin{tabular}{llll}
\hline Reperfusion therapy & No. (\%) & $\begin{array}{l}\text { Mortality } \\
\text { No. (\%) }\end{array}$ & $P$ \\
\hline No reperfusion & $54(12)$ & $12(22.2)$ & $0.001^{*}$ \\
Thrombolytic therapy & $290(64.4)$ & $18(6.2)$ & \\
Primary PCI & $74(16.4)$ & $5(6.7)$ & \\
Rescue PCI & $32(7.1)$ & $1(3.1)$ & \\
\hline
\end{tabular}

Data expressed as number (\%)

$\mathrm{PCl}$ percutaneous coronary intervention ${ }^{*} P<0.05$

Effects of admission vital signs and physiological predictors on the in-hospital prognosis of STEMI patients

Vital signs have received considerable research interest in the epidemiological studies concerned with STEMI risk prediction because of their importance in expressing the physiological and pathological cardiac changes. Tachycardia reflects the sympathetic overactivity, high myocardial oxygen consumption, and myocardial work in patients with STEMI $[24,25]$. The blood pressure reflects the extent of myocardial damage and subsequently predicts the mortality [26].

Table 5 Univariate logistic regression in prediction of mortality in the studied group

\begin{tabular}{|c|c|c|c|}
\hline Variable & Coefficient $(\beta)$ & $P$ & OR $(95 \% \mathrm{Cl})$ \\
\hline \multicolumn{4}{|l|}{ Clinical predictors } \\
\hline Age (years) & 0.074 & $<0.0001^{* *}$ & $1.077(1.04-1.114)$ \\
\hline Gender & 1.129 & $0.002^{*}$ & $3.091(1.489-6.417)$ \\
\hline Diabetes mellitus & 0.443 & 0.204 & $1.557(0.787-3.082)$ \\
\hline Hypertension & -0.420 & 0.264 & $0.657(0.315-1.372)$ \\
\hline \multicolumn{4}{|l|}{ Laboratory predictors } \\
\hline $\begin{array}{l}\text { Hemoglobin } \\
\text { (gm/dl) }\end{array}$ & -0.400 & $<0.0001^{* *}$ & $0.670(0.549-0.819)$ \\
\hline NL-ratio & -3.982 & 0.424 & $0.019(0.00-323.363)$ \\
\hline $\begin{array}{l}\text { Cardiac troponin } \\
\text { (positive) }\end{array}$ & 1.277 & $0.006^{*}$ & $3.585(1.44-8.922)$ \\
\hline CK-MB (IU/ml) & 0.002 & $0.041^{*}$ & $1.002(1-1.003)$ \\
\hline $\begin{array}{l}\text { eGFR }(\mathrm{ml} / \mathrm{min} / \\
\left.1.73 \mathrm{~m}^{2}\right)\end{array}$ & -0.034 & $<0.0001^{* *}$ & $0.967(0.954-0.98)$ \\
\hline \multicolumn{4}{|c|}{ Physiological predictors } \\
\hline SI & 2.782 & $<0.0001^{* *}$ & $16.151(5.801-44.962)$ \\
\hline MSI & 2.129 & $<0.0001^{* *}$ & $8.411(3.935-17.976)$ \\
\hline Killip score & 1.323 & $<0.0001^{* *}$ & $3.755(2.753-5.121)$ \\
\hline Age-SI & .056 & $<0.0001^{* *}$ & $1.057(1.038-1.077)$ \\
\hline MAP & -.057 & $<0.0001^{* *}$ & $0.945(0.925-0.966)$ \\
\hline
\end{tabular}

$O R$ odds ratio, $\mathrm{Cl}$ confidence interval, NL-ratio neutrophil lymphocyte ratio, eGFR estimated glomerular filtration rate, SI shock index, MSI modified shock index, Age-Si age shock index, MAP mean arterial pressure

${ }^{*} P<0.05$

**P $<0.0001$
Table 6 Multivariate logistic regression model in prediction of mortality in the studied group

\begin{tabular}{llll}
\hline Variable & Coefficient $(\beta)$ & $P$ & $\mathrm{OR}(95 \% \mathrm{Cl})$ \\
\hline SI & 3.352 & $<0.0001^{* *}$ & $28.562(8-101.979)$ \\
$\begin{array}{l}\text { Cardiac troponin } \\
\text { (positive) }\end{array}$ & 1.064 & $0.035^{*}$ & $2.898(1.081-7.772)$ \\
Age (years) & .069 & $0.002^{*}$ & $1.072(1.026-1.2)$ \\
eGFR $\left(\mathrm{ml} / \mathrm{min} / 1.73 \mathrm{~m}^{2}\right)$ & -.018 & $0.041^{*}$ & $0.982(0.965-0.999)$ \\
Constant & -8.941 & $<0.0001^{* *}$ & 0.000 \\
\hline
\end{tabular}

$S /$ shoch index, eGFR estimated glomerular filtration rate, OR odds ratio, $\mathrm{Cl}$ confidence interval

${ }^{*} P<0.05$

$* * P<0.000$

The combination of more than one factor is always better than relying on a single one, and this motivated many researchers to test multiple indices with different components of vital signs to predict the risk magnitude among STEMI patients. Of those, SI [27] and MSI [28, 29] were the most proven to have a significant relation to mortality and adverse outcomes in STEMI with higher prediction power of MSI over the SI [30]. High Killip class was also described as a predictor of mortality in STEMI patients [31]. In the present study, we found that SI, MSI, MAP, SI-AGE, and Killip score were all significantly related to mortality with the highest coefficient and odds to the SI. Based on these results, SI was chosen for the multivariate prediction model.

\section{Effects of admission cardiac enzymes and hemoglobin on the in-hospital prognosis of STEMI patients}

The value of cardiac enzymes represents the infarction extent and size and is associated with the magnitude of myocardial necrosis and in-hospital mortality in STEMI patients [32]. Our study reported that either cardiac troponin positivity or the increase in CK-MB levels was associated with increased mortality risk with higher odds for troponin positivity. This is in contrast to a published report that showed higher predictability and prognostic significance for CK-MB levels [15].

In patients of acute STEMI, low baseline HB behaved independently as a risk factor for increased 30-day event rates [33]. In line with this report, we also found a positive correlation between the lower HB levels and mortality in STEMI patients.

Multivariate model was constructed from combination of clinical, laboratory, and physiological predictors of the highest coefficients and odds. We found that the most significant predictors of in-hospital mortality for STEMI in our setting were SI, cardiac troponin positivity, age, and eGFR. The model has the advantage of ease of application as it is based on simple clinical signs and routine laboratory assessment.

There were few limitations of our study. First, our study was a single-center study. Second, we used the qualitative 


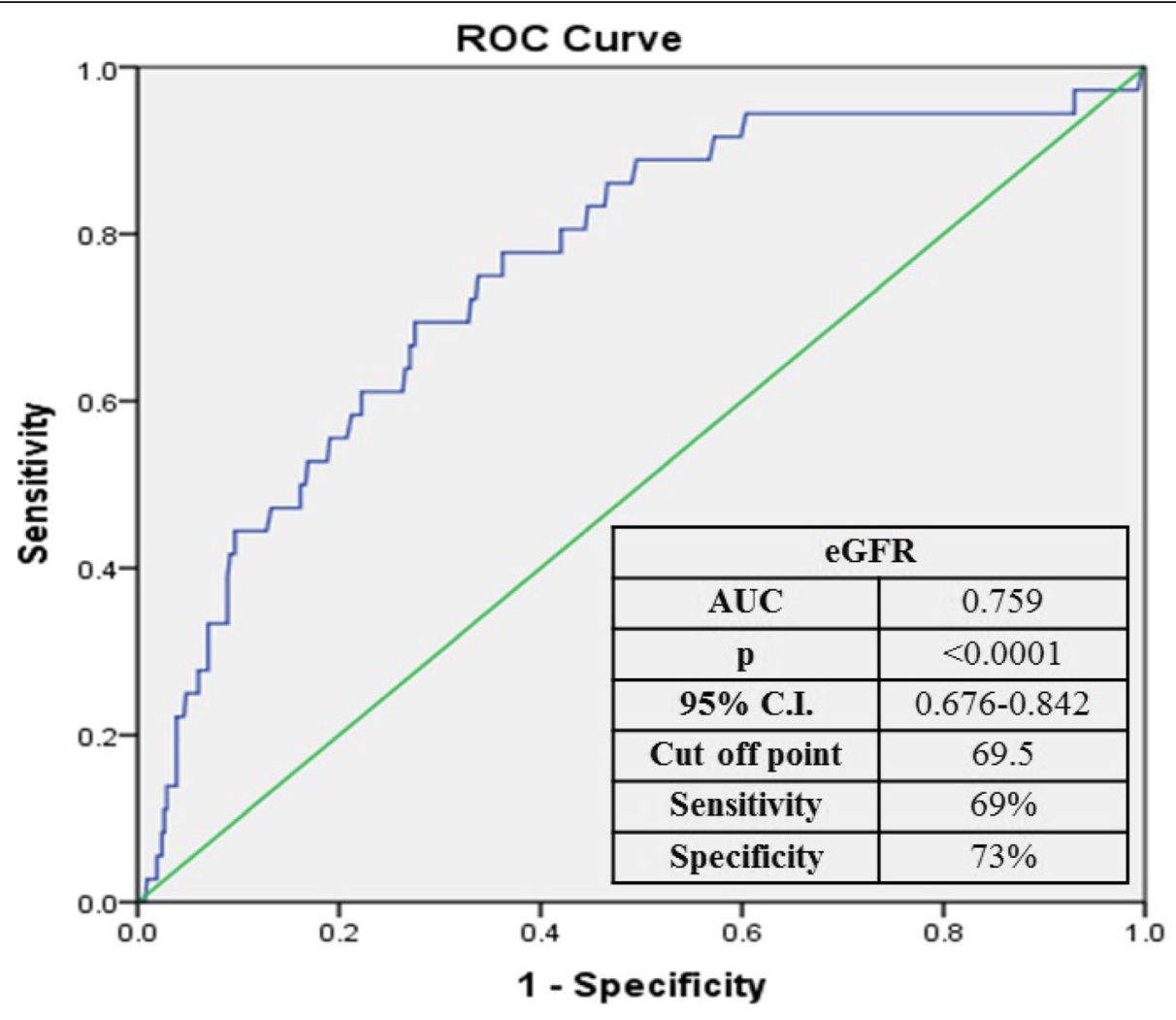

Diagonal segments are produced by ties.

Fig. 1 ROC curve for eGFR as a predictor of mortality. eGFR, estimated glomerular filtration rate; Cl, confidence interval

test of cardiac troponin due to limited resources. Third, it had short-term follow-up till the patients' discharge only. Although the results were significant in such period, short- and long-term follow-up analysis is required, which is undergoing and will be stated.

\section{Conclusion}

In conclusion, eGFR, age, SI, and cardiac troponin are valid to construct a prediction model for mortality in STEMI patients. However, more studies including higher number of patients, from different centers, and longer follow-up are required.

\section{Abbreviations}

AF: Atrial fibrillation; BMI: Body mass index; CAD: Coronary artery disease; CKD-EPI: Chronic Kidney Disease Epidemiology Collaboration; CKMB: Creatine kinase MB fraction; DBP: Diastolic blood pressure; DM: Diabetes mellitus; eGFR: Estimated glomerular filtration ratio; HB: Hemoglobin; HF: Heart failure; HR: Heart rate; HTN: Hypertension; MAP: Mean arterial pressure; MSI: Modified shock index; PCl: Percutaneous coronary intervention; SBP: Systolic blood pressure; SI: Shock index; STEMI: ST elevation anterior myocardial infarction

\section{Acknowledgements}

None

\section{Authors' contributions}

MW did the data collection and paper editing. ES, MKN, and MMA established the results and did the formatting of the paper. All authors read and approved the final manuscript.

Funding

Authors did not receive funds from any organizations or persons.

\section{Availability of data and materials}

All data generated or analyzed during this study are available from the corresponding author on reasonable request

\section{Ethics approval and consent to participate}

This study was approved by the Institutional Review Board of Mansoura Faculty of Medicine (IRB code MS 19.04.567). This study was carried out in accordance with the rules of the Helsinki Declaration. Informed written consent was obtained from all the participants

\section{Consent for publication}

Not applicable

\section{Competing interests}

The authors certify that they have no affiliations with or involvement in any organization or entity with any financial interest, or non-financial interest in the subject matter or materials discussed in this manuscript. The results presented in this paper have not been published previously in whole or part, except in abstract format.

\section{Author details}

'Department of Cardiology, Faculty of Medicine, Mansoura University, Mansoura, Egypt. ${ }^{2}$ Mansoura Nephrology and Dialysis Unit, Faculty of Medicine, Mansoura University, Mansoura, Egypt. 
Received: 21 December 2019 Accepted: 15 May 2020

Published online: 01 June 2020

\section{References}

1. Joseph $\mathrm{P}$, Leong $\mathrm{D}$, Mckee $\mathrm{M}$, et al. Reducing the global burden of cardiovascular disease, part 1: the epidemiology and risk factors. Circulation research. Sep 1 2017;121(6):677-694

2. Horiuchi Y, Aoki J, Tanabe K et al (2018) A high level of blood urea nitrogen is a significant predictor for in-hospital mortality in patients with acute myocardial infarction. International heart journal. 59(2):263-271

3. Ibanez B, James S, Agewall S et al (Dec 2017) 2017 ESC Guidelines for the management of acute myocardial infarction in patients presenting with STsegment elevation. Revista espanola de cardiologia. 70(12):1082

4. Lee PT, Chao TH, Huang YL, et al. Analysis of the clinical characteristics, management, and causes of death in patients with STEMI treated with primary percutaneous coronary intervention from 2005 to 2014. Int Heart J. Sep 28 2016;57(5):541-546.

5. Anavekar NS, McMurray JJ, Velazquez EJ et al (2004) Relation between renal dysfunction and cardiovascular outcomes after myocardial infarction. New England Journal of Medicine. 351(13):1285-1295

6. Levey AS, Stevens LA, Schmid CH, et al. A new equation to estimate glomerular filtration rate. Annals of internal medicine. May 5 2009;150(9): 604-612.

7. Sloan EP, Koenigsberg M, Clark JM, Weir WB, Philbin N (Nov 2014) SI and prediction of traumatic hemorrhagic shock 28-day mortality: data from the DCLHb resuscitation clinical trials. The western journal of emergency medicine. 15(7):795-802

8. Kilic T, Ermis H, Gulbas $\mathrm{G}$ et al (2014) Prognostic role of the simplified pulmonary embolism severity index and SI in pulmonary embolism. Polskie Archiwum Medycyny Wewnetrznej. 124(12):678-687

9. Guo ZJ, Lin Q, Zi XR et al (Apr 2015) Correlation of computed tomography angiography parameters and $\mathrm{SI}$ to assess the transportation risk in aortic dissection patients. La Radiologia medica. 120(4):386-392

10. Bilkova D, Motovska Z, Widimsky P, Dvorak J, Lisa L, Budesinsky T (Nov-Dec 2011) SI: a simple clinical parameter for quick mortality risk assessment in acute myocardial infarction. The Canadian journal of cardiology. 27(6):739-742

11. O'Gara PT, Kushner FG, Ascheim DD, et al. 2013 ACCF/AHA guideline for the management of STEMI: a report of the American College of Cardiology Foundation/American Heart Association Task Force on Practice Guidelines. Journal of the American College of Cardiology. Jan 29 2013;61(4):e78-e140.

12. Lee KL, Woodlief LH, Topol EJ, et al. Predictors of 30-day mortality in the era of reperfusion for acute myocardial infarction. Results from an international trial of 41,021 patients. GUSTO-I Investigators. Circulation. Mar 15 1995;91(6): $1659-1668$.

13. KDIGO AKI (2012) Work Group: KDIGO clinical practice guideline for acute kidney injury. Kidney Int Suppl 2:1-138

14. Wang $R$, Mei B, Liao $X$, et al. Determination of risk factors affecting the inhospital prognosis of patients with acute STEMI after percutaneous coronary intervention. BMC cardiovascular disorders. Sep 12 2017;17(1):243.

15. Peduzzi P, Concato J, Kemper E, Holford TR, Feinstein AR (1996) A simulation study of the number of events per variable in logistic regression analysis. Journal of clinical epidemiology. 49(12):1373-1379

16. Haller PM, Jager B, Farhan S et al (Mar 2018) Impact of age on short- and long-term mortality of patients with STEMI in the VIENNA STEMI network. Wiener klinische Wochenschrift. 130(5-6):172-181

17. Potluri R, Mathew A, Carter $P$ et al (2018) P3687 The influence of age and comorbidity on STEMI outcomes: a risk/benefit paradox? European heart journal 39(suppl_1):ehy563-eP3687

18. Guo Y, Yin F, Fan C, Wang Z (Jul 2018) Gender difference in clinical outcomes of the patients with CAD after percutaneous coronary intervention: a systematic review and meta-analysis. Medicine. 97(30):e11644

19. De Luca G, Gibson CM, Bellandi F et al (2009) DM is associated with distal embolization, impaired myocardial perfusion, and higher mortality in patients with ST-segment elevation myocardial infarction treated with primary angioplasty and glycoprotein IIb-Illa inhibitors. Atherosclerosis. 207(1):181-185

20. Saluveer $\mathrm{O}$, Redfors $\mathrm{B}$, Angerås $\mathrm{O}$ et al (2017) HTN is associated with increased mortality in patients with ischaemic heart disease after revascularization with percutaneous coronary intervention-a report from SCAAR. Blood pressure. 26(3):166-173
21. Zhao L, Wang L, Zhang Y (Oct 2009) Elevated admission serum creatinine predicts poor myocardial blood flow and one-year mortality in ST-segment elevation myocardial infarction patients undergoing primary percutaneous coronary intervention. The Journal of invasive cardiology. 21(10):493-498

22. Choi JS, Kim CS, Bae EH, et al. Suboptimal medical care of patients with STelevation myocardial infarction and renal insufficiency: results from the Korea Acute Myocardial Infarction Registry. BMC nephrology. Sep 11 2012; 13:110.

23. Bataille $Y$, Costerousse $O$, Bertrand OF, Moranne O, Pottel H, Delanaye P (2018) One-year mortality of patients with ST-Elevation myocardial infarction: Prognostic impact of creatinine-based equations to estimate glomerular filtration rate. PloS one. 13(7):e0199773

24. Graham LN, Smith PA, Stoker JB, Mackintosh AF, Mary DA (2002) Time course of sympathetic neural hyperactivity after uncomplicated acute myocardial infarction. Circulation. 106(7):793-797

25. Hogarth AJ, Graham LN, Mary DA, Greenwood JP (Jul 2009) Gender differences in sympathetic neural activation following uncomplicated acute myocardial infarction. European heart journal. 30(14):1764-1770

26. Ruiz-Bailen M, de Hoyos EA, Reina-Toral A et al (Mar 2004) Paradoxical effect of smoking in the Spanish population with acute myocardial infarction or unstable angina: results of the ARIAM Register. Chest. 125(3):831-840

27. Chambers MW, Whitsel EA, Stouffer G et al (2018) Performance of prestabilization SI as a predictor of mortality in patients admitted with stsegment elevation myocardial infarction: the atherosclerosis risk in communities surveillance study. Journal of the American College of Cardiology. 71(11):A239

28. Faria Da Mota T, Azevedo P, Bispo J et al (2018) P6418 Modified SI-an independent predictor of acute HF and in-hospital mortality in patients with ST-segment elevation myocardial infarction. European heart journal 39(suppl_1):ehy566-eP6418

29. Ali M, Butt UM, Hameed MH (2019) Raised modified SI (MSI) as a predictor of inhospital mortality in patients with ST-segment elevation myocardial infarction (STEMI). Pakistan Heart Journal 51(4)

30. Gouda M, Saad A, Al-Daydamony M (2016) Modified SI as a predictor of inhospital outcome in cases of ST-segment elevation myocardial infarction treated with primary percutaneous coronary intervention. J Cardiol Curr Res. 7(4):00255

31. El-Menyar A, Zubaid M, AlMahmeed W et al (2012) Killip classification in patients with acute coronary syndrome: insight from a multicenter registry. The American journal of emergency medicine. 30(1):97-103

32. Christenson RH, Vollmer RT, Ohman EM et al (2000) Relation of temporal creatine kinase-MB release and outcome after thrombolytic therapy for acute myocardial infarction. The American journal of cardiology. 85(5):543-547

33. Agrawal R, Nath R, Pandit N, Raj A (2018) Baseline HB and creatinine clearance as independent risk factors for 30-day event rate in patients of acute ST-elevation myocardial infarction undergoing primary percutaneous coronary intervention. Heart India. 6(4):127

\section{Publisher's Note}

Springer Nature remains neutral with regard to jurisdictional claims in published maps and institutional affiliations.

\section{Submit your manuscript to a SpringerOpen ${ }^{\circ}$ journal and benefit from:}

- Convenient online submission

- Rigorous peer review

- Open access: articles freely available online

High visibility within the field

- Retaining the copyright to your article

Submit your next manuscript at $>$ springeropen.com 